Blackburn, T. H. \& Hobson, P. N. (1960). J. gen. Microbiol. 22, 282-289

\title{
Isolation of Proteolytic Bacteria from the Sheep Rumen
}

\author{
BY T. H. BLACKBURN AND P. N. HOBSON \\ Rowett Research Institute, Bucksburn, Aberdeen
}

\begin{abstract}
SUMMARY: Several different culture media were used in attempts to isolate the bacteria from the sheep rumen. Only a small proportion of the bacteria which developed were actively proteolytic, and these belonged to a limited number of types. These bacteria were found in sheep on different diets, but comparison with the proteolytic activity of whole rumen contents suggests that they represented only a fraction of the proteolytic organisms of the rumen.
\end{abstract}

The measurement of the proteolytic activity of whole and fractionated rumen contents is described in Blackburn \& Hobson (1960). In the present paper are described attempts to isolate the bacteria responsible for this proteolytic activity. Media containing protein were used so that the proteolytic activity could be measured at stages in the isolation procedure, but to obtain adequate growth additions of non-protein nitrogen had to be made. Some rumen bacteria were found to need rumen fluid as a nitrogen source or to provide growth factors, but many bacteria which were initially isolated in rumen fluid media were later found to grow in other media, so yeast extract was used in most of the media described here to give a more uniform medium for determination of proteolysis.

\section{METHODS}

Determination of proteolytic activity. The quantitative biuret method used was described in Blackburn \& Hobson (1960). For qualitative determinations of proteolysis on solid media clearing of the cloudy medium around colonies was looked for either immediately, or after flooding with acid mercuric chloride. Semi-quantitative tests on liquid media were initially made by centrifuging off the organisms and adding trichloroacetic acid solution ( 3 vol. $0.72 \mathrm{M})$ to a portion of the culture; the turbidity produced being compared against an uninoculated culture. As initial standards the turbidity produced by different concentrations of casein was measured under the same conditions. Later it was found unnecessary to centrifuge off the organisms.

Reagents were described in Blackburn \& Hobson (1960).

\section{Media}

Medium 1. The mineral solutions used were based on those of Hungate (1950) and contained: (a) $0.3 \%$ (w/v) $\mathrm{K}_{2} \mathrm{HPO}_{4}$; (b) (\% w/v). 0.3, $\mathrm{KH}_{2} \mathrm{PO}_{4}$; $0 \cdot 6,\left(\mathrm{NH}_{4}\right)_{2} \mathrm{SO}_{4} ; 0 \cdot 6, \mathrm{NaCl} ; 0 \cdot 6, \mathrm{MgSO}_{4} \cdot 7 \mathrm{H}_{2} \mathrm{O} ; 0 \cdot 6, \mathrm{CaCl}_{2} ;(c) L$-cysteine hydrochloride, 0.2 g.; $\mathrm{NaHCO}_{3}, 1.92 \mathrm{~g}$; ; in water $32 \mathrm{ml}$. A mixture was made usually containing, per $100 \mathrm{ml}$. : solution (a), $15 \mathrm{ml}$.; solution (b) $15 \mathrm{ml}$.; $0 \cdot 1 \%$ resazurin solution, $0.1 \mathrm{ml}$.; protein $0.5 \mathrm{~g}$. (based on $\mathrm{N}$ content of the material); yeast 
extract, $0.5 \mathrm{~g}$; water to $100 \mathrm{ml}$. This mixture was autoclaved at $120^{\circ}$ for $15 \mathrm{~min}$. and gassed with sterile $\mathrm{CO}_{2}$. Sterile filtered solution $(c), 8 \cdot 3 \mathrm{ml}$, and sterile glucose solution to give a final concentration of $0.3 \%(w / v)$ were then added. The whole medium (medium 1) was gassed with $\mathrm{CO}_{2}$ and dispensed and incubated in $9 \mathrm{ml}$. amounts under $\mathrm{CO}_{2}$; the final $\mathrm{pH}$ was 6.5-7. Agar at $0.05 \%(w / v)$ or $1.5 \%(w / v)$ gave the semi-solid or solid media.

Medium 2. Reinforced clostridial medium was prepared as described by Hirsch \& Grinsted (1954).

Medium 3. Casein yeast liquid medium contained (per $100 \mathrm{ml}$.); solution $(a), 15 \mathrm{ml}$.; solution (b), $15 \mathrm{ml}$; yeast extract $0.5 \mathrm{~g}$.; casein, $0.5 \mathrm{~g}$.; cysteine hydrochloride, $\mathbf{0 . 0 5}$ g.; and water. After steaming to disperse the casein and yeast extract the medium was autoclaved $\left(120^{\circ}\right.$ for $15 \mathrm{~min}$.), gassed with $\mathrm{CO}_{2}$, dispensed into suitable volumes under $\mathrm{CO}_{2}$ and incubated under $\mathrm{CO}_{2}$; final $\mathrm{pH}$ c. 7 .

Medium 4. Modified reinforced clostridial medium contained, g./100 ml.; Bacto-peptone, 2; Lab-Lemco, 2; Yeastrel, 0.6; soluble starch, 0.2; sodium acetate, 1; casein, 0.5; and water. After steaming the medium was filtered through paper pulp and autoclaved, then filtered solution $(c), 8 \cdot 3 \mathrm{ml}$, was added and the medium dispensed and incubated under $\mathrm{CO}_{2}$. For a solid medium agar, $1.5 \mathrm{~g}$. was added and in some experiments glucose, $0.3 \mathrm{~g}$. was included.

Medium 5. Rumen fluid media were made on the same basis as medium 1 but rumen fluid, cleared by centrifugation at $18,000 \mathrm{~g}$ for $20 \mathrm{~min}$. and added at $20 \mathrm{ml} . / 100 \mathrm{ml}$. medium before autoclaving, replaced the yeast extract and part of the water.

Preparation of inoculum. Rumen samples were taken, usually about $2 \mathrm{hr}$. after feeding from sheep fitted with permanent rumen cannulae. After straining the sample through muslin and lightly centrifuging to remove the coarser particles tenfold dilutions were made directly in semi-solid medium 1 , or in the salt solution base of medium 1 under $\mathrm{CO}_{2}$, and portions of these dilutions added to the growth media. All incubations were carried out at $37^{\circ}$.

Sheep. Unless otherwise stated the sheep used were fed on the hay and concentrates diet described in Blackburn \& Hobson (1960).

\section{RESULTS}

Each type of medium was tested with a number of samples of rumen contents. The results given are a summary of a large number of observations made over many months.

\section{Medium 1, containing fish meal or casein as protein source}

As proteinases can be specific in their substrates white fish meal, which has an amino acid content similar to that of yeast extract and which was one of the proteins being fed to the sheep, was included in some media to see whether it evoked a specific flora. Other variations of the medium contained casein. Both proteins were used with and without addition of glucose and yeast extract. From the initial cultures subcultures were made into semi-solid 
medium 1 and then on to solid medium 1 where proteolysis was tested. A selection of the bacteria growing in medium $1+$ fish meal were tested for proteolysis of casein and gelatin and the bacteria growing in casein-containing medium 1 were tested for proteolysis of fish meal. All substrates tested were equally readily hydrolysed. Samples were taken from two sheep over a period of months and the results obtained were all very similar. Representative results are shown in Table 1 , the lesser dilutions having a more varied flora. Since similar bacteria grew whichever protein was used later media all contained casein to provide a more uniform substrate.

Table 1. Bacteria growing in the highest dilutions of rumen contents in different semi-solid media incubated anaerobically

\begin{tabular}{|c|c|c|c|c|c|c|c|c|}
\hline \multirow[b]{2}{*}{$\begin{array}{l}\text { Sheep } \\
a\end{array}$} & \multicolumn{8}{|c|}{ Medium and growth in highest dilutions } \\
\hline & $\begin{array}{c}\text { F } \\
\text { G-v rods } \\
10^{-6}\end{array}$ & $\begin{array}{c}\text { FG } \\
\text { G+ cocci } \\
10^{-8}\end{array}$ & $\begin{array}{l}\text { FY } \\
-\end{array}$ & $\begin{array}{l}\text { FYG } \\
\text { G+ cocci, } \\
\text { G - rods } \\
\text { and other } \\
\text { types } \\
10^{-8}\end{array}$ & $\frac{\text { CYG }}{-}$ & $\underline{\mathbf{C Y}}$ & $\begin{array}{c}\text { GY } \\
-\end{array}$ & $\underset{\substack{\text { MCMed } \\
10^{-}}}{\underbrace{}_{\text {M }}}$ \\
\hline$b$ & $\begin{array}{l}\text { G-v rods } \\
10^{-4} \\
10^{-5}\end{array}$ & $\begin{array}{c}\mathbf{G}+\text { cocci } \\
10^{-8}\end{array}$ & $\begin{array}{l}\text { G-v rods } \\
10^{-5}\end{array}$ & $\begin{array}{c}G+\text { cocci, } \\
10^{-7}, 10^{-8}\end{array}$ & $\begin{array}{l}G+\text { cocci } \\
\text { few } G- \\
\text { rods } 10^{-6} \\
G+\text { cocci } \\
10^{-8}\end{array}$ & $\begin{array}{l}\text { G- rods } \\
\text { G+ } \\
\text { granular } \\
\text { rods } 10^{-5}\end{array}$ & $\begin{array}{l}\text { G- rods } \\
\text { G+ } \\
\text { large, } \\
\text { rods. } \\
\text { G+ G- } \\
\text { cocci in } \\
\text { chains } \\
10^{-5} \text {. } \\
\text { G+ } \\
\text { cocci } \\
10^{-7}\end{array}$ & 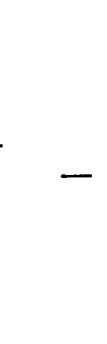 \\
\hline
\end{tabular}

F, fish meal; G, glucose; $Y$, yeast extract; $C$, casein, additives to basal salts solution described in the text. RCM, Reinforced clostridial medium. This gave an estimate of the total numbers of bacteria present. Both sheep were on a hay and concentrates diet. G+, G-, G-v, Gram-positive, -negative, -variable.

Samples from eleven sheep on different diets of grass or hay alone or with concentrate supplements were tested in the casein-containing medium 1 , with results similar to those given in Table 1. Growth was obtained from $10^{-5}$ to $10^{-9}$ dilutions depending on the medium, with Gram-negative rods, or, in glucose-containing media, Gram-positive cocci predominating.

In these experiments proteolysis was tested on plate cultures incubated anaerobically; only a small proportion of the bacteria which grew in the initial cultures showed active proteolysis. So that more strictly anaerobic conditions could be maintained during the experiments other dilutions of rumen contents from one sheep were inoculated into roll tubes of casein yeast medium. Growth in the initial cultures occurred up to $10^{-10}$ dilution. Again the main proteolytic bacteria which grew were small pleomorphic Gramnegative or variable rods, with some coccoid or short stout Gram-negative granulated rods. As before, only a small proportion of the colonies which developed in the medium were actively proteolytic, but all later experiments with solid media were done in roll tubes to ensure anaerobic conditions. 
Casein yeast liquid medium

Proteolysis was often difficult to detect on solid media, so a more quantitative method was sought. Determination of the residual protein by the biuret reaction proved suitable. Two of the proteolytic cocci and rods isolated in the first experiments were tested for proteolytic activity in casein yeast liquid medium (medium 3 ), and in this medium $+0.8 \%$ glucose. The glucose caused an $85 \%$ inhibition of proteolysis by the cocci, and $50 \%$ by the rods, probably owing to acid formation, so it was omitted from later experiments. No growth was obtained without the yeast extract. Twenty-four isolates from the initial experiments, mainly Gram-positive cocci and Gram-negative rods, with some Gram-positive rods, were tested for growth and proteolytic activity in medium 3. All showed growth and proteolytic activity in this medium. Proteolytic strains were obtained from initial cultures in media with no casein; these and later experiments where subcultures from a large number of initial dilutions in different media were carried through casein-containing media showed that no selection of proteolytic types was made by the presence of casein in the medium. The proteolysis noted on solid media was confirmed in the liquid medium and some bacteria which appeared to be non-proteolytic on solid media were proteolytic in the liquid medium.

Attempts were the made to obtain proteolytic bacteria by using medium 3 and quantitatively assessing the degree of proteolysis occurring at different times as a guide to subculturing. In a representative experiment the initial cultures from diluted rumen fluid showed proteolysis due to endogenous proteinases (in medium under toluene) to a dilution of $10^{-2}$. In growing cultures proteolysis took place to the $10^{-4}$ dilution after incubation for 2 days, to $10^{-6}$ after 4 days and to $10^{-7}$ after 6 days. The bacteria growing in these dilutions were mainly Gram-positive cocci and coccobacilli, with some Gram-negative straight and curved rods and large Gram-positive rods. On subculturing by dilution into medium 3 proteolytic activity was found, but the flora remained mixed, as many of the bacteria seemed to be present in much the same numbers. In further experiments some of these bacteria were obtained in pure culture by using the solidified medium, but they were of the same limited number of types as before.

Since cysteine has been reported to inhibit proteolysis by some bacterial enzymes (see, for instance, Oakley \& Warrack, 1958), similar experiments were made by using medium 3 without cysteine $(a)$, or with thioglycollic acid, $0.1 \%$ but without cysteine (b). It was difficult to keep medium $(a)$ reduced, but the bacteria which grew were similar to those in the normal medium, and proteolytic activity was much the same. In medium $(b)$ little growth was obtained and proteolysis occurred only in the culture inoculated with a $10^{-1}$ dilution of rumen contents. 


\section{Modified reinforced clostridial medium}

Dilutions of rumen contents were cultured in modified reinforced clostridial medium (medium 4) with and without glucose and also in the solidified medium. Subcultures were made in the same media. The results were much as before, proteolysis in the original cultures and initial subcultures was caused by Gram-positive cocci and rods; on continued subcultivation the cocci became only feebly proteolytic.

\section{Rumen fluid medium}

Dilutions of rumen contents were cultured in rumen fluid medium (medium 5) with and without glucose. Slightly better growth was obtained in the medium with glucose, but the extent of proteolysis was much the same, occurring up to $10^{-6}$ or $10^{-7}$ dilution. Although Gram-positive cocci and rods grew in all the dilutions which showed proteolysis, Gram-negative curved rods also grew in larger numbers than in other media. In roll tubes of medium 5 growth was greatly increased by adding glucose, appearing up to $10^{-10}$ dilution $\left(10^{-6}\right.$ without glucose), but no definitely proteolytic colonies were detected.

\section{Fractionation of rumen contents and culture in casein yeast medium}

Rumen contents were fractionated under aseptic conditions as previously described (Blackburn \& Hobson, 1960) except that the sediments were not washed, and so small bacteria might be more generally distributed than in the fractions used in the previous work. The fractions, and also the larger debris removed in the initial straining through gauze, were suspended in sterile saline to the original volume of rumen sample and then diluted tenfold in a solution, made up from solutions $a, b$, and $c$ in the proportions of medium 1 , under $\mathrm{CO}_{2}$ and gently shaken for $1 \mathrm{hr}$. at $37^{\circ}$. Whole unstrained rumen fluid was similarly treated. It was hoped by this procedure to disperse any clumps of organisms caused by centrifugation and to dislodge proteolytic bacteria attached to food particles. The suspensions were then further diluted and inoculated into yeast casein medium (medium 3). Growth and proteolysis were tested after incubation for 2 and 6 days. A poor growth was obtained up to $10^{-5}$ dilution of the strained-off debris. The other fractions showed better growth up to $10^{-7}$ dilution with proteolysis to $10^{-5}$ or $10^{-6}$. The bacteria growing from all the fractions were similar to those from whole rumen contents and on further subcultivation from the higher dilutions the proteolytic types appeared to be the same as before, namely, Gram-positive cocci and rods and Gram-negative coccobacilli.

\section{Properties of some of the bacteria isolated}

Since only a few morphological types were obtained in early tests the experiments were designed mainly to see whether more of the morphological types of bacteria seen in the original rumen contents could be obtained and shown to be proteolytic, rather than to obtain a large number of pure cultures of similar type for detailed examination. In all media extensive proteolysis 
took place in the initial cultures which contained a mixed flora. As this flora was fractionated proteolytic activity tended to become less and only a few actively proteolytic types were finally obtained. Even amongst bacteria of similar morphological types usually only certain strains were proteolytic. In some cases, although active proteolysis took place in mixed culture, no proteolytic types were obtained on subcultivation.

The bacteria described below were isolated at various times during the experiments and were representative of the types which generally grew in all the media and which occurred in numbers up to $c .10^{6}$ to $10^{8} / \mathrm{ml}$. rumen contents.

Gram-positive streptococci. Proteolytic and non-proteolytic strains were obtained all with similar properties. All were small $(1 \mu)$ cocci in pairs or short chains. Although growth took place in air it was enhanced by anaerobic conditions, and colonies on solid media were whitish and mucoid. Indole, Voges-Proskauer, catalase and urease tests were negative, nitrate was not reduced and no growth was obtained in Koser's citrate medium or on MacConkey agar. Growth occurred in 6.5\% NaCl but not at pH 9.6 and no haemolysis was observed. The cocci were not amylolytic, but fermented a wide range of carbohydrates, including mannitol, to acid without gas. All were serologically of group D, but do not correspond exactly with any rumen streptococci so far isolated.

Gram-positive micrococci. These appeared actively proteolytic on first isolation, but became only feebly so on continued culture. The cocci were $1 \mu$ diameter, mainly in pairs. All were facultatively anaerobic, with white colonies and were $\beta$-haemolytic when incubated aerobically. Ammonia, but not $\mathrm{H}_{2} \mathrm{~S}$ was produced, methyl red and Voges-Proskauer tests were positive, indole negative. No growth occurred on MacConkey agar. All fermented glucose, fructose, sucrose, galactose and maltose, and two out of seven strains fermented lactose, giving acid but no gas. Extracts gave no reaction with group D streptococcal antiserum.

Gram-negative rods. All the ten isolates tested in detail were Gram-negative irregularly staining small, motile, facultatively anaerobic, coccobacilli or short rods. Proteolytic strains produced a red pigment, non-proteolytic ones were white. Proteolytic strains grew well on MacConkey agar, but acid production was doubtful because of the red pigment produced aerobically (at $37^{\circ}$ ); anaerobically a faint red coloration was formed. None was haemolytic. Nitrate was reduced to nitrite and five out of six proteolytic strains grew in citrate medium, but not at pH 9.6. All were catalase positive, but were urease negative and did not produce ammonia. Indole was negative for proteolytic strains, positive for non-proteolytic, and the Voges-Proskauer reaction was positive for two proteolytic strains. All strains were non-amylolytic, but acid, without gas, was produced from a number of sugars. Other small Gram-negative coccobacilli were isolated, but these appeared to lose proteolytic activity on subcultivation.

Gram-positive rods. Gram-positive or variable sporing rods with a spreading proteolytic growth appeared at intervals in all media. They appeared to belong to the genus Bacillus and were not further characterized. One type of 
anerobic Gram-variable rod with a spherical terminal spore, growing up to $10^{-5}$ dilution in casein yeast media and isolated over a short period was identified by the Bacteriology Department of the University of Leeds as an 'atypical, non-toxigenic variant of Clostridium tetani'.

\section{DISCUSSION}

The authors (Blackburn \& Hobson, 1960) have shown that proteolysis by whole rumen contents takes place and that the proteolytic activity appeared to be distributed over the whole range of rumen micro-organisms. The attempts to isolate actively proteolytic bacteria have resulted in a limited number of types being obtained, although a more varied growth took place in the cultures containing the lowest dilutions of rumen contents. Our results agree with those of other workers (Appleby, 1955; Gilroy, 1957; Hunt \& Moore, 1958) in that although anaerobic conditions were maintained during the isolations nearly all the final isolates were facultative anaerobes. However, whilst Bacillus types have appeared at intervals they have never become the predominating proteolytic types, although under certain conditions they might, for a short time at least, grow in large numbers in the rumen. The sporing bacteria often appeared to increase in numbers in several sheep at the same time, suggesting that the bacteria were being introduced into the rumen in a common foodstuff such as the hay. For instance Appleby (1955) and Gutierrez (1953) found the same bacteria on hay and in the rumens of animals fed on it. Whilst there are a large number of facultative anaerobes in the sheep rumen, many bacteria which cause the breakdown of such substrates as cellulose have been shown to be strict anaerobes. This suggests that we have isolated only a small proportion of the proteolytic bacteria and, since proteolysis was always extensive in mixed cultures, the total breakdown of protein in the rumen may be caused by several kinds of bacteria acting together. However, the types of bacteria described here have been found in a number of sheep on different rations and have appeared in the same animals over a long period, so they must play a part in rumen proteolysis. Although the presence of proteolytic zones around colonies on solid media was often difficult to detect, and more obvious proteolysis took place in liquid media (suggesting that the proteolytic enzymes are not readily diffusible) the results show that different proteolytic bacteria were not being lost through adherence to the larger plant particles which were usually strained off the rumen samples, as the same types were cultured from the food particles as from other fractions.

None of the larger bacteria which seemed by fractionation experiments to be actively proteolytic appeared in the media used even when fractions enriched in these organisms were cultured. The liquid rumen fluid based medium did grow more of the curved Gram-negative rods which have been shown to be important in carbohydrate metabolism in the bovine rumen, and variations on this type of medium might result in more types of proteolytic bacteria being obtained.

Even amongst the morphological types of bacteria isolated, only a small 
proportion was actively proteolytic, as Appleby (1955) found. Experiments have shown, however, that these bacteria produce much more hydrolysed protein in the medium than is utilized by their own growth, so that a comparatively small number of such bacteria could provide sufficient non-protein nitrogen for growth of other rumen species.

\section{REFERENCES}

AppleBy, J. C. (1955). The isolation and classification of proteolytic bacteria from the rumen of the sheep. J. gen. Microbiol. 12, 526 .

Blackburn, T. H. \& Hobson, P. N. (1960). Proteolysis in the sheep rumen by whole and fractionated rumen contents. J. gen. Microbiol. 22, 272.

GruRoy, J. J. (1957). Nitrogen Requirements for Growth of Bovine Rumen Bacteria. Ph.D. Thesis, Maryland University.

GuTIERREz, J. (1953). Numbers and characteristics of lactate utilizing organisms in the rumen of cattle. J. Bact. 66, 123.

Hrrsch, A. \& Grinsted, E. (1954). Methods for the growth and enumeration of anaerobic spore-formers from cheese. J. Dairy Res. 21, 101.

Hungate, R. E. (1950). The anaerobic mesophilic cellulolytic bacteria. Bact. Rev. $14,1$.

Hunt, W. G. \& Moore, R. O. (1958). The proteolytic system of a Gram-negative rod isolated from the bovine rumen. Appl. Microbiol. 6, 36 .

OAKnEY, C. L. \& WARrack, G. H. (1958). The cysteine-inactivated proteinase ( $\delta$-antigen) of Clostridium histolyticum. J. gen. Microbiol. 18, 9.

(Received 25 August 1959) 